\title{
Removal of Cd2+ from Water Containing Ca2+, Mg2+ using Titanate Nanotubes Modified by Carbon
}

\author{
Mingda Wu \\ Nanjing Tech University \\ Nanjing Tech University \\ Tao Zhou \\ Nanjing Tech University \\ Yi Ma \\ Nanjing Tech University \\ Zhengsong Weng \\ Nanjing Tech University
}

Linghong Lu ( $\square$ linghonglu@njtech.edu.cn )

\section{Research Article}

Keywords: Water treatment, Cadmium ion, Titanate nanotubes, carbon-modification

Posted Date: October 29th, 2021

DOI: https://doi.org/10.21203/rs.3.rs-991276/v1

License: (c) (i) This work is licensed under a Creative Commons Attribution 4.0 International License. Read Full License

Version of Record: A version of this preprint was published at Environmental Science and Pollution Research on February 9th, 2022. See the published version at https://doi.org/10.1007/s11356-02219002-7. 
and\&nbsp;Cadmium standard\&nbsp;solution\&nbsp;(1000 ug/mL in

$4 \quad 1 \mathrm{~mol} / \mathrm{L} \mathrm{HCl}$ ) were purchased from Shanghai Aladdin Biochemical

5 Technology Co., Ltd. Furfuryl alcohol (\&gt;99\%), Ethanol, Calcium

6 chloride anhydrous $(\mathrm{CaCl}<\mathrm{sub}>2</$ sub $>$, \&gt;99\%) and Cadmium hexahydrate $(\mathrm{MgCl}<$ sub $>2</$ sub $>$ \&middot; $6 \mathrm{H}<$ sub $>2</$ sub $>0)$ and 

$<$ p $>3$ g\&nbsp; $\mathrm{TiO}<$ sub $>2</$ sub $>$ and 1 g Furfuryl alcohol were mixed with $10 \mathrm{~mL}$ Ethanol. After stirring for 12 hours, the furfuryl alcohol in the mixed suspension was polymerized at $80 \& d e g ; C$, and then calcined at $600 \& d e g ; C$ for 3 hours under a nitrogen atmosphere. This was how $\mathrm{TiO} 2 / \mathrm{C}$ was made. he making process of

replaced with $\mathrm{TiO} 2 / \mathrm{C} .</ \mathrm{p}>$

$<\mathrm{p}>2.2 .3$ Preparation of $\mathrm{TiO}<\mathrm{sub}>2</ \mathrm{sub}>/ \mathrm{HC}$ and $\mathrm{TNT} / \mathrm{HC}</ \mathrm{p}>$ $<$ p $>$ Treat TiO2/C in boiling $\mathrm{HNO}<\mathrm{sub}>3</$ sub $>$ for 6 hours. After standing, the supernatant was poured out, washed with deionized water to neutrality, and dried at $105 \& \mathrm{deg} ; \mathrm{C}$ to obtain a $\mathrm{TiO} 2 / \mathrm{HC}$ sample (Maroto-Valer et al. 2004). The making process of TNT/HC was the same as that of TNT, except that the $\mathrm{TiO}<\mathrm{sub}>2</$ sub $>$ was replaced with $\mathrm{TiO}<\mathrm{sub}>2</ \mathrm{sub}>/ \mathrm{HC} .</ \mathrm{p}>$ $<\mathrm{p}>$ The synthesis process of the adsorbent is shown in figure $1 .</ \mathrm{p}>$ $<\mathrm{p}>2.3$ Characterization of adsorbent $</ \mathrm{p}>$ $<\mathrm{p}>$ The\&nbsp;morphology of these adsorbents\&nbsp;was observed\&nbsp;by SEM (Tescan, A VEGA) and TEM\&nbsp;(JEM2100Plus).\&nbsp; The structures of these three samples were studied by XRD (Panalytical X\&apos;Pert PRO MPD).\&nbsp;The carbon 

(NETZSCH STA 409\&nbsp;PC/PG).\&nbsp;FT-IR (TENSOR 27, resolution $4 \mathrm{~cm}<$ sup $>$ \&minus; $1</$ sup $>$, Bruker, Billerica, MA, USA) was used to analyze the functional groups and bonding conditions on the surface of the adsorption material. XPS (K-ALPHA, Thermo Fisher, Waltham, MA, USA) was used to analyze the surface element composition and valence state of the surface. The concentration of $\mathrm{Cd}<\sup >2+</$ sup $>$ was detected by A flame atomic absorption spectrophotometer (FLAAS) (AA900T, PerkinElmer, Waltham, MA, USA). $</ \mathrm{p}>$ $<\mathrm{p}>2.4$ Adsorption experiments $<$ p $>$ $<\mathrm{p}>$ All batch experiments were repeated 3 times and oscillated at a speed of $200 \mathrm{rpm}$ at the set temperature. The general experimental procedure is described as follows: All batch experiments were carried out by adding $0.02 \mathrm{~g}$ adsorbent to polyethylene pipe $(50 \mathrm{ml})$ with $40 \mathrm{ml}$ solutions. When Initial solution concentration is 200 $\mathrm{mg} / \mathrm{L}$ with the $\mathrm{pH}$ from 2 to 6 , the most suitable $\mathrm{pH}$ for the adsorption of $\mathrm{Cd}<\sup >2+</$ sup $>$ by TNT, TNT/C, and TNT/HC is first determined. At 25\&deg; $\mathrm{C}$ and the optimum $\mathrm{pH}$, the adsorption isotherm is obtained by experimenting with initial solutions of different concentrations. At the same time, the adsorption kinetic 
data was obtained by testing the adsorption capacity under different contact time intervals. $</ \mathrm{p}>$

$<\mathrm{p}>$ After the set adsorption time is reached, the supernatant obtained after filtering the aqueous suspension through a 0.45 um filter membrane can be used for the measurement of $\mathrm{Cd}<\sup >2+</$ sup $>$ concentration.\&nbsp; $</ \mathrm{p}>$

$<\mathrm{p}>$ The data is the average of three experiments. The adsorption capacity qe (mg/g) was calculated by the eq. (1) (Zhu et al.

$$
\begin{aligned}
& 2018)</ \text { p }> \\
& <\text { p }><\text { img }
\end{aligned}
$$

src="https://myfiles.space/user_files/69515_16346c490bab499e/695

$$
\text { 15_custom_files/img1635490867.png" }></ \text { p }>
$$
$<\mathrm{p}>$ Where $\operatorname{co}(\mathrm{mg} / \mathrm{L})$ is the concentration of initial $\mathrm{Cd} 2+$ concentration and $\mathrm{Ce}(\mathrm{mg} / \mathrm{L})$ is the equilibrium $\mathrm{Cd} 2+$ concentration, respectively, $\mathrm{V}(\mathrm{L})$ is the volume of the solution and $\mathrm{m}(\mathrm{g})$ is the weight of sorbent. $</ \mathrm{p}>$ Removal of $\mathrm{Cd}^{2+}$ from water containing $\mathrm{Ca}^{2+}$, $\mathrm{Mg}^{2+}$ using Titanate nanotubes modified by carbon Mingda Wu, Linghong Lu* ${ }^{*}$ Tao Zhou, Yi Ma, Zhengsong Weng College of Chemical Engineering, State Key Laboratory of Materials-oriented Chemical Engineering, Nanjing Tech University, Nanjing 211816, P.R. China

\footnotetext{
"Corresponding Author E-mail: linghonglu@njtech.edu.cn (L.H. Lu)
} 


\section{Abstract}

$\mathrm{Ca}^{2+}$ and $\mathrm{Mg}^{2+}$ usually exist in natural water. When $\mathrm{Cd}^{2+}$ is removed from water by adsorption, it will be inhibited by these two ions. Titanate nanotubes (TNTs) have an effective adsorption capacity for $\mathrm{Cd}^{2+}$ due to extraordinary ion-exchange property. However, TNTs also adsorb $\mathrm{Ca}^{2+}$ and $\mathrm{Mg}^{2+}$ in water. In this study, carbon-modified TNT (TNT/C or TNT/HC) was synthesized by hydrothermal synthesis. The transmission electron microscope (TEM) images show that TNT/C or TNT/HC still keep nanotube morphology. The experimental results show the order of adsorption amount to $\mathrm{Cd}^{2+}$ is TNT $>$ TNT/C $>$ TNT/HC when there is no $\mathrm{Ca}^{2+}$ or $\mathrm{Mg}^{2+}$. But when there is $\mathrm{Ca}^{2+}$ or $\mathrm{Mg}^{2+}$ in the water, the order of $\mathrm{Cd}^{2+}$ adsorption capacity becomes TNT/HC $>$ TNT/C $>$ TNT. It indicates that the surface carbon-modification can alleviate the hindrance of $\mathrm{Ca}^{2+}$ or $\mathrm{Mg}^{2+}$ to $\mathrm{Cd}^{2+}$ removal. This is because the carbon on the surface of TNT captured part of $\mathrm{Ca}^{2+}$ or $\mathrm{Mg}^{2+}$, it made more $\mathrm{Cd}^{2+}$ be successfully absorbed by TNT through ion exchange. This mechanism was confirmed by XPS spectra analysis. The results of this paper can provide ideas for the adsorption and removal of $\mathrm{Cd}^{2+}$ in water in the presence of $\mathrm{Ca}^{2+}$ or $\mathrm{Mg}^{2+}$.

\section{Keywords}

Water treatment; Cadmium ion; Titanate nanotubes; carbon-modification

\section{Introduction}

With the increase of cadmium production year by year, a considerable amount of cadmium is discharged into the environment, and many natural water systems are polluted by cadmium (Zhao et al. 2011). Unreasonable disposal of heavy metalcontaining wastewater poses a huge threat to human health (Zhou et al. 2018). Cadmium ion $\left(\mathrm{Cd}^{2+}\right)$ is on is one of the toxic ions, and the In the World Health Organization's regulations on qualified drinking water, the maximum concentration of $\mathrm{Cd} 2+$ is limited to $5 \mathrm{ug} / \mathrm{L}$ (Sriram et al. 2020). The effects of intaking the drinking water whose $\mathrm{Cd}^{2+}$ concentration exceeds the limit ingestion are inducing kidney disease and 
111 bone disease (Zhang et al. 2019). The Japanese "itai-itai" disease is the worst event in

112 the $\mathrm{Cd}^{2+}$ pollution incident, and it is included in the eight major pollution 113 incidents(Huang et al. 2020a).

114 There are many methods to treat water with heavy metal ions, including physical 115 methods, chemical methods, membrane treatment methods, and electrolysis methods 116 (Bolisetty et al. 2019). Among them, the adsorption method has become one of the most 117 promising methods for the treatment of metal ions due to its low cost, simple operation 118 process, and less post-treatment (Mudhoo et al. 2020). However, traditional adsorbents, 119 such as carbon-based adsorbents and organic polymer adsorbents, do not have a good 120 adsorption capability on $\mathrm{Cd}^{2+}(\mathrm{Lu} \&$ Astruc 2018). In contrast, nano-metal oxide 121 materials have shown potential applications in anchoring $\mathrm{Cd}^{2+}$. Among them, 122 magnesium oxide, iron oxide, manganese oxide, and aluminum oxide have all been 123 used as adsorbents for heavy metal ions (Boparai et al. 2011, Mahdavi et al. 2013, Yusuf 124 et al. 2020, Zhang et al. 2020). However, due to the instability of these substances in 125 water, these oxides are not enough to be perfect $\mathrm{Cd}^{2+}$ adsorbent materials. Titanate 126 nanotubes have attracted the attention of researchers since it successfully prepared by 127 Tomoko Kasuga in 1998 (Kasuga et al. 1998), it has received extensive attention from 128 researchers due to their excellent specific surface area, excellent hydrophilicity and 129 stability in complex water environments. This material is generally obtained by one130 step hydrothermal treatment of titanium dioxide in a high-concentration $\mathrm{NaOH}$ aqueous 131 solution at medium temperature $\left(90-180^{\circ} \mathrm{C}\right)$, and could be obtained from various crystal 132 forms of titanium oxide raw materials (Bi et al. 2020). Allen J. Du et al. found that when 133 there are both inner sphere complexation and ion exchange, the multi-site ion 134 complexation (CDMUSIC) model based on charge distribution is the most consistent 135 with the process of TNT adsorption of $\mathrm{Cd}^{2+}$ (Du et al. 2011). Xiong et al. found that 136 with the $\mathrm{pH}$ of the initial solution changed from 2 to 6 , the ability of $\mathrm{Cd}^{2+}$ adsorbed by 137 TNT was increased (Xiong et al. 2011). In addition, it was confirmed that $0.1 \mathrm{M}$ 138 hydrochloric acid can desorb $85 \%$ of $\mathrm{Cd}^{2+}$ from the adsorbent (Xiong et al. 2011). Liu 
et al. found that $\mathrm{Na}^{+}, \mathrm{K}^{+}, \mathrm{Ca}^{2+}$ and $\mathrm{Mg}^{2+}$ will compete with $\mathrm{Cd}^{2+}$, which greatly inhibited

140 the adsorption of $\mathrm{Cd}^{2+}$ (Liu et al. 2013). Moreover, it is proposed that EDTA and $\mathrm{HNO}_{3}$

141 can also be used as desorption agents to desorb $\mathrm{Cd}^{2+}$ from TNT, and the desorption rate 142 can reach more than $90 \%$ (Liu et al. 2013). Moreover, it was proved that the [ $\mathrm{TiO}_{6}$ ]

143 octahedral structure of TNTs hardly changed during the entire adsorption process(Duan 144 et al. 2021). This shows that TNT has high structural stability when facing the complex environment of the waste water (Wang et al. 2013a). Wang et al. used $0.1 \mathrm{M} \mathrm{HNO}_{3}$ to

146 desorb the $\mathrm{Cd}^{2+}$ in TNT, and then only $0.2 \mathrm{M} \mathrm{NaOH}$ at room temperature could easily 147 achieve the regeneration of TNT. Even after six cycles, the regenerated TNT can adsorb $148 \mathrm{Cd}^{2+}$ (Wang et al. 2013b). The research results show low $\mathrm{NaOH}$ concentration is required to prepare TNT with the largest adsorption capacity for $\mathrm{Cd}^{2+}$ (Liu et al. 2014).

150 Yang et al. successfully prepared a magnetite-graphene oxide-titanate composite 151 material, which made the titanate material easier to recycle. (Yang et al. 2020).

Although titanate materials (TNT or TNs) have great potential as cadmium ion 153 adsorbents, when it is surrounded by $\mathrm{Na}^{+}, \mathrm{K}^{+}, \mathrm{Ca}^{2+}, \mathrm{Mg}^{2+}$ and natural organic matter 154 (NOM), the adsorption capacity of $\mathrm{Cd}^{2+}$ would be greatly reduced. The powdered activated carbon supported TNTs (TNTs@PAC) synthesized by Ma et al. showed high 156 adsorption capacity for $\mathrm{Pb}(\mathrm{II})$ and strong resistance to natural organic matter (Ma et al. 157 2017). This shows that the researchers found that the environment affects the adsorption 158 of titanate. However, few researchers are interested in the effect of inorganic ions on 159 the adsorption of titanate. $\mathrm{Ca}^{2+}$ and $\mathrm{Mg}^{2+}$ often appear in polluted water bodies, they 160 would reduce the adsorption capacity of titanate materials for $\mathrm{Cd}^{2+}$ : from $2.02 \mathrm{mmol} / \mathrm{g}$ 161 to $1.17 \mathrm{mmol} / \mathrm{g}$ (Liu et al. 2013). According to the soft and hard acid-base theory, $162 \mathrm{Ca}^{2+}$ and $\mathrm{Mg}^{2+}$ belong to the ranks of hard acid, while $\mathrm{Cd}^{2+}$ is classified as soft 163 acid(Esrafili et al. 2021, Wang et al. 2019). In addition, some carbon-containing

164 functional groups, such as $-\mathrm{COOH},-\mathrm{C}=\mathrm{O}$ and $\mathrm{C}-\mathrm{OH}$, are in the category of hard bases 165 (Di Natale et al. 2020, Zhao et al. 2011). If the surface of the Titanate material is functionalized with $-\mathrm{COOH},-\mathrm{C}=\mathrm{O}$ and $-\mathrm{OH}$, they would be used to capture $\mathrm{Ca}^{2+}, \mathrm{Mg}^{2+}$, 
and the probability of ion exchange between these interfering ions and the sodium ions

168 in the titanate layer would be reduced. It is beneficial to the adsorption of $\mathrm{Cd}^{2+}$.

169 Based on the above statement, after carbonizing the furfuryl alcohol on the surface

170 of the titanium oxide, it was further processed by alkaline hydrothermal method to 171 obtain in-situ carbon-supported TNT.

172 This article aims to:

173 1) Synthesis of Titanate nanotubes modified by carbon (TNT/C);

174 2) Evaluate the selective adsorption performance of TNT/C;

1753 ) Explore the mechanism of resisting interference from non-target ions by oxidizing 176 surface carbon with nitric acid.

177

\section{Experimental}

\subsection{Materials and reagents}

$\mathrm{TiO}_{2}$ (anatase, $\left.2-5 \mathrm{~nm}, 98 \%\right)$ and Cadmium standard solution $(1000 \mathrm{ug} / \mathrm{mL}$ in $1 \mathrm{~mol} / \mathrm{L}$

$181 \mathrm{HCl})$ were purchased from Shanghai Aladdin Biochemical Technology Co., Ltd.

182 Furfuryl alcohol (>99\%), Ethanol, Calcium chloride anhydrous $\left(\mathrm{CaCl}_{2},>99 \%\right)$ and 183 Cadmium nitrate tetrahydrate $(>99 \%)$ were obtained from Sinopharm Chemical 184 Reagent Co., Ltd (Shanghai, China). Magnesium chloride hexahydrate $\left(\mathrm{MgCl}_{2} \cdot 6 \mathrm{H}_{2} \mathrm{O}\right)$ 185 and Sodium hydroxide $(\mathrm{NaOH},>99 \%)$ were both acquired from XiLong Scientific Co., 186 Ltd (Guangdong, China).

\subsection{Preparation of TNT, TNT/C and TNT/HC}

\subsubsection{Preparation of TNT}

Mix $1.2 \mathrm{~g}$ of $\mathrm{TiO} 2$ with $60 \mathrm{~mL}$ of $10 \mathrm{M} \mathrm{NaOH}$ solution. After stirring overnight, 191 the mixture was poured into a container lined with polytetrafluoroethylene, and then 192 heated at $130^{\circ} \mathrm{C}$ for 3 days. Until the temperature of the mixed solution was consistent 193 with room temperature, rinsed the sample with pure water until the supernatant reached 194 neutrality. Then the target product was sonicated in alcohol and lastly dried at $80^{\circ} \mathrm{C}(\mathrm{Li}$ 
et al. 2015).

196

2.2.2 Preparation of $\mathrm{TiO}_{2} / \mathrm{C}$ and $\mathrm{TNT} / \mathrm{C}$

198

$3 \mathrm{~g} \mathrm{TiO}_{2}$ and $1 \mathrm{~g}$ Furfuryl alcohol were mixed with $10 \mathrm{~mL}$ Ethanol. After stirring

199 for 12 hours, the furfuryl alcohol in the mixed suspension was polymerized at $80^{\circ} \mathrm{C}$, 200 and then calcined at $600^{\circ} \mathrm{C}$ for 3 hours under a nitrogen atmosphere. This was how $201 \mathrm{TiO} 2 / \mathrm{C}$ was made. he making process of TNT/C was the same as that of TNTs, except 202 that the $\mathrm{TiO} 2$ was replaced with $\mathrm{TiO} 2 / \mathrm{C}$.

203

2.2.3 Preparation of $\mathrm{TiO}_{2} / \mathrm{HC}$ and $\mathrm{TNT} / \mathrm{HC}$

Treat $\mathrm{TiO} 2 / \mathrm{C}$ in boiling $\mathrm{HNO}_{3}$ for 6 hours. After standing, the supernatant was 206 poured out, washed with deionized water to neutrality, and dried at $105^{\circ} \mathrm{C}$ to obtain a $207 \mathrm{TiO} 2 / \mathrm{HC}$ sample (Maroto-Valer et al. 2004). The making process of TNT/HC was the 208 same as that of TNT, except that the $\mathrm{TiO}_{2}$ was replaced with $\mathrm{TiO}_{2} / \mathrm{HC}$.

The synthesis process of the adsorbent is shown in figure 1 .
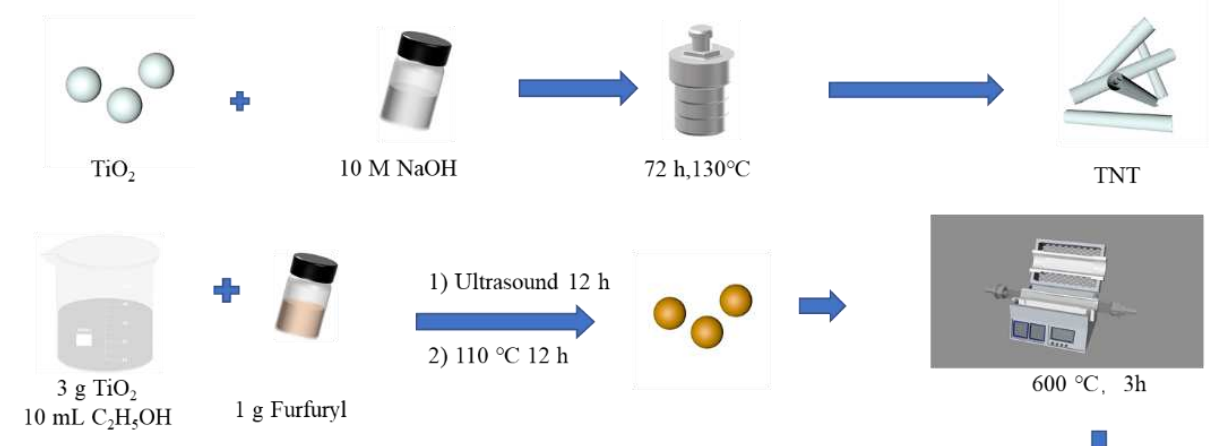

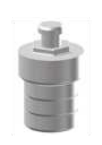

Stir $24 \mathrm{~h}$

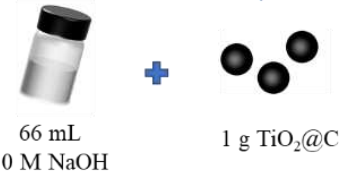

TNT@C

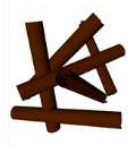

1) Wash to neutral

2) $90{ }^{\circ} \mathrm{C} 12 \mathrm{~h}$

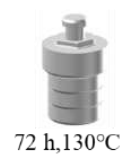

TNT@HC
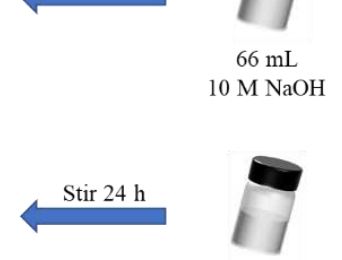

$66 \mathrm{~mL}$ $10 \mathrm{M} \mathrm{NaOH}$

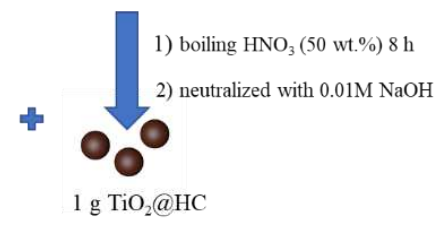

Fig. 1. The scheme of the synthesis of TNT, TNT/C and TNT/HC. 
The morphology of these adsorbents was observed by SEM (Tescan, A VEGA)

215 and TEM (JEM-2100Plus). The structures of these three samples were studied by XRD

216 (Panalytical X'Pert PRO MPD). The carbon content of the composite material was

217 determined from TGA (NETZSCH STA 409 PC/PG). FT-IR (TENSOR 27, resolution

$2184 \mathrm{~cm}^{-1}$, Bruker, Billerica, MA, USA) was used to analyze the functional groups and

219 bonding conditions on the surface of the adsorption material. XPS (K-ALPHA, Thermo

220 Fisher, Waltham, MA, USA) was used to analyze the surface element composition and

221 valence state of the surface. The concentration of $\mathrm{Cd}^{2+}$ was detected by A flame atomic

222 absorption spectrophotometer (FLAAS) (AA900T, PerkinElmer, Waltham, MA, USA).

\section{$224 \quad 2.4$ Adsorption experiments}

All batch experiments were repeated 3 times and oscillated at a speed of $200 \mathrm{rpm}$ at the set temperature. The general experimental procedure is described as follows: All batch experiments were carried out by adding $0.02 \mathrm{~g}$ adsorbent to polyethylene pipe (50 $\mathrm{ml}$ ) with $40 \mathrm{ml}$ solutions. When Initial solution concentration is $200 \mathrm{mg} / \mathrm{L}$ with the $\mathrm{pH}$ from 2 to 6 , the most suitable $\mathrm{pH}$ for the adsorption of $\mathrm{Cd}^{2+}$ by TNT, TNT/C, and $\mathrm{TNT} / \mathrm{HC}$ is first determined. At $25^{\circ} \mathrm{C}$ and the optimum $\mathrm{pH}$, the adsorption isotherm is obtained by experimenting with initial solutions of different concentrations. At the same

232 time, the adsorption kinetic data was obtained by testing the adsorption capacity under different contact time intervals.

After the set adsorption time is reached, the supernatant obtained after filtering the aqueous suspension through a $0.45 \mathrm{um}$ filter membrane can be used for the measurement of $\mathrm{Cd}^{2+}$ concentration.

The data is the average of three experiments. The adsorption capacity $q_{e}(\mathrm{mg} / \mathrm{g})$

238 was calculated by the Eq. (1) (Zhu et al. 2018)

$239 q_{e}=\left(c_{0}-c_{e}\right) * V / m$

240 Where $c_{0}(\mathrm{mg} / \mathrm{L})$ is the concentration of initial $\mathrm{Cd}^{2+}$ concentration and $c_{e}(\mathrm{mg} / \mathrm{L})$ is

241 the equilibrium $\mathrm{Cd}^{2+}$ concentration, respectively, $V(\mathrm{~L})$ is the volume of the solution 242 and $m(\mathrm{~g})$ is the weight of sorbent. 


\section{Results and discussions}

\section{3.1 Characterization}

246 Figure 2 shows the SEM images of three adsorbents (TNT, TNT/C, TNT/HC). The 247 samples all showed some aggregation. In order to prove that these bundles or clusters 248 of material structures are nanotubes rather than nanowires, TEM was used for further 249 characterization.

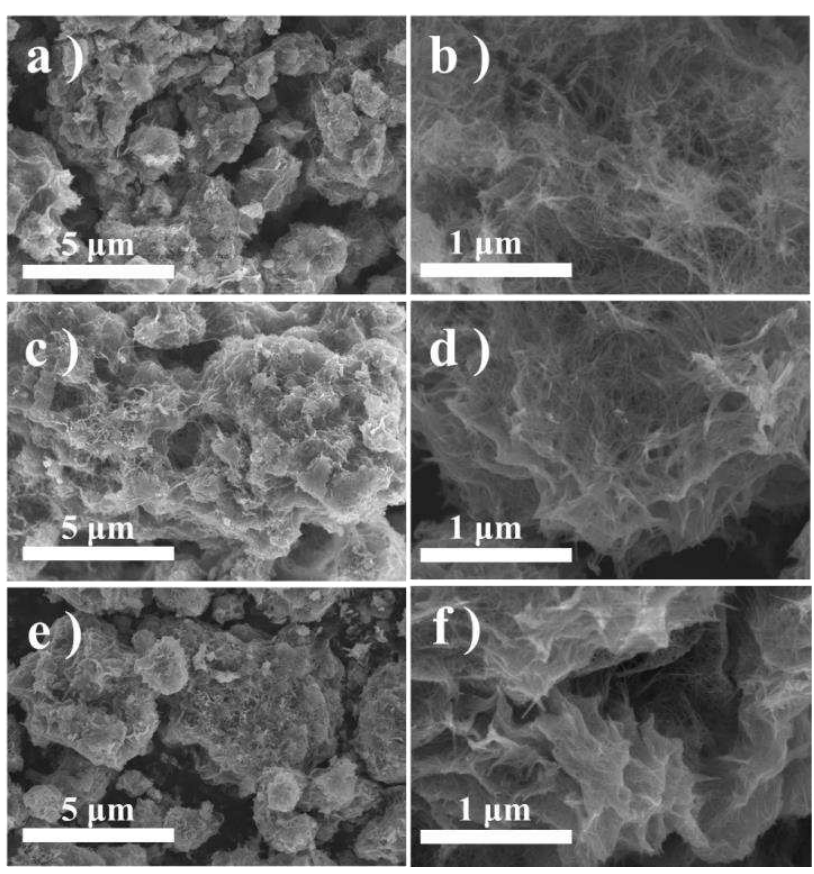

Fig. 2. SEM images of TNT (a, b),TNT@C (c, d) and TNT@HC (e, f)

Figure 3 demonstrates a typical TEM image of titanate nanotubes, which are 255 approximately 5-10 $\mathrm{nm}$ in diameter. Figure 4.a. shows the XRD patterns of the TNT, $256 \mathrm{TNT} / \mathrm{C}$ and TNT/HC. It is assumed that the peaks at the center of $10^{\circ}, 24.3^{\circ}, 28.5^{\circ}$ and $25748.2^{\circ}$ are their characteristic diffraction peaks, which indicates that the synthesized 258 titanate nanotubes have the chemical formula of $\mathrm{Na}_{\mathrm{x}} \mathrm{H}_{2-\mathrm{x}} \mathrm{Ti}_{3} \mathrm{O}_{7}$ (Duan et al. 2021). The 259 peak at $10^{\circ}$ is an indication of the interlayer distance of titanate (Zhao et al. 2016). The 260 SEM/TEM images and XRD patterns of TNT, TNT/C and TNT/HC are similar, which 
means that carbon loading on the $\mathrm{TiO}_{2}$ surface does not affect the growth of TNT.
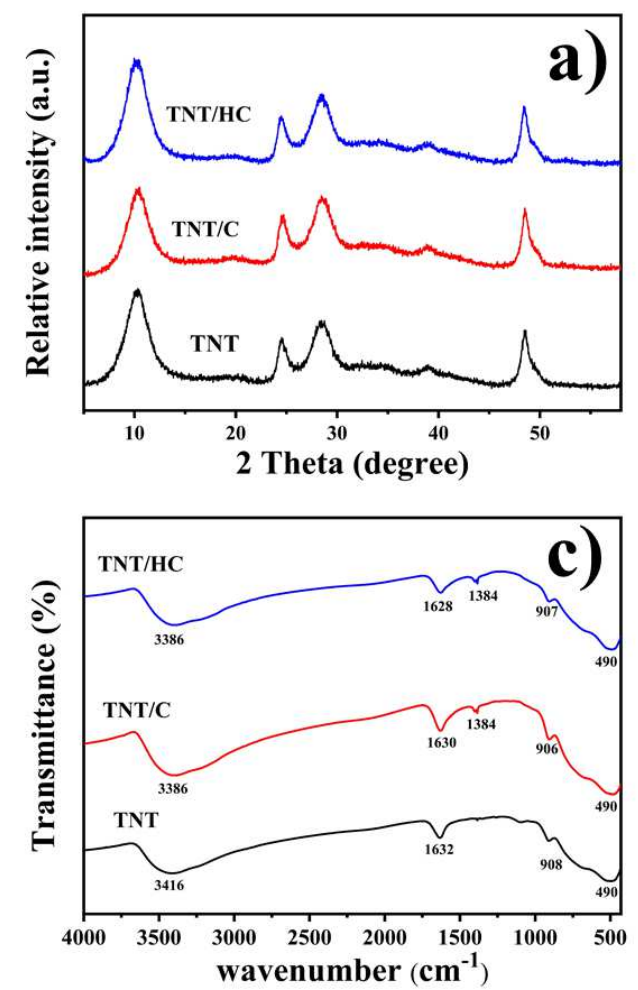
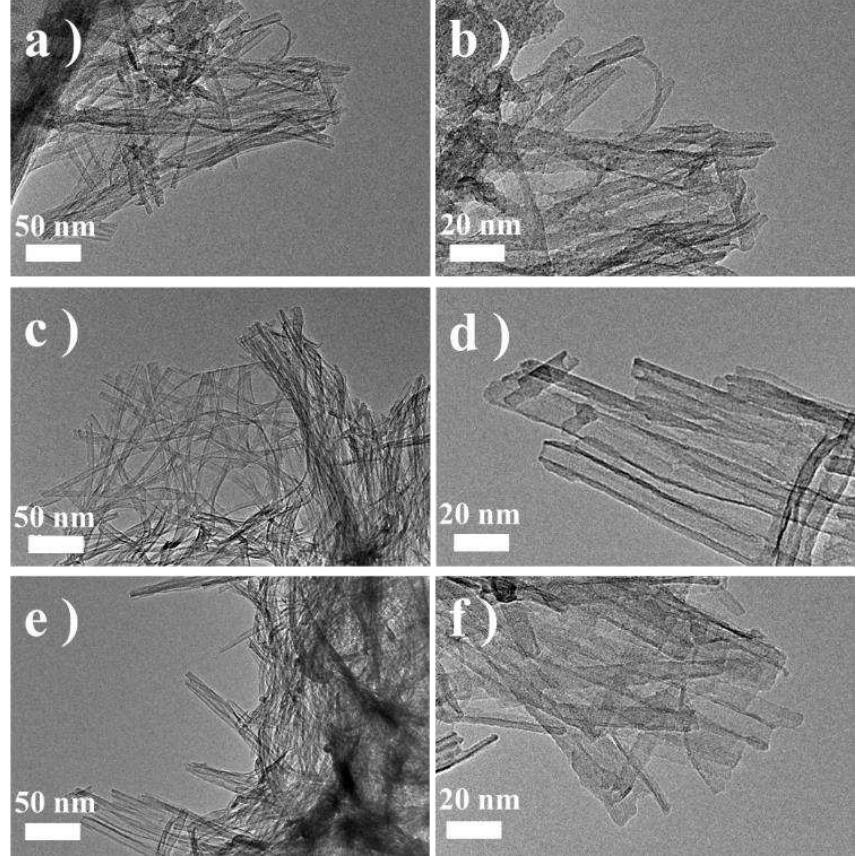

Fig.3. TEM images of TNT $(a, b)$, TNT/C $(c, d)$ and TNT/HC $(e, f)$

Fig. 4. Characterizations of the TNT, TNT/C and TNT/HC. (a) XRD pattern, (b)
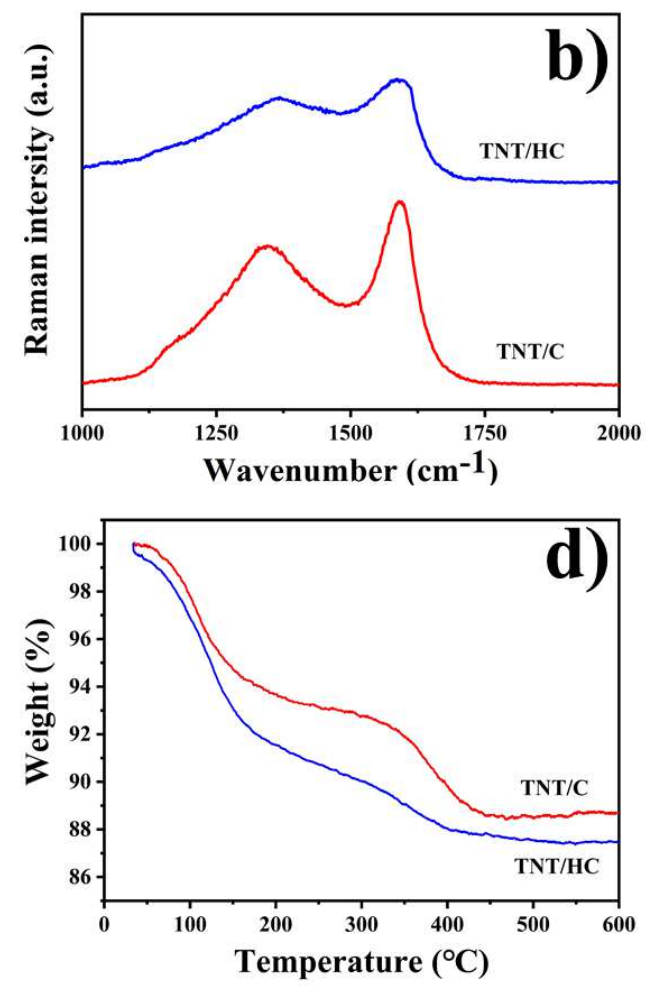

Raman spectra, (c) FT-IR spectra, (d) Thermogravimetric profiles. 
268 peaks at $1358 \mathrm{~cm}^{-1}$ and $1600 \mathrm{~cm}^{-1}$ correspond to the $\mathrm{G}$ peak and D peak of carbon, 269 which indicates the successful introduction of carbon (Pyrzyńska \&Bystrzejewski 270 2010). The $\mathrm{I}_{\mathrm{D}} / \mathrm{I}_{\mathrm{G}} \mathrm{TNT} / \mathrm{HC}(0.884)$ exceeding $\mathrm{I}_{\mathrm{D}} / \mathrm{I}_{\mathrm{G}} \mathrm{TNT} / \mathrm{C}(0.806)$ indicates that the degree 271 of non-graphitization of TNT/HC is greater than that of TNT/C, which is caused by 272 nitric acid treatment. The FT-IR spectra of TNT, TNT/C and TNT/HC are given in 273 Figure 4.c. For the neat TNT, the strong absorption bands in the region of $3416 \mathrm{~cm}^{-1}$ 274 and the band at $1632 \mathrm{~cm}^{-1}$ could be attributed to the hydroxyl groups stretching 275 vibration and water molecules binding vibration, respectively, indicating the presence 276 of hydroxyl groups and water molecules in the TNT (Wang et al. 2018, Zhu et al. 2018). 277 The band at $908 \mathrm{~cm}^{-1}$ might be related to a four-coordinate $\mathrm{Ti}^{-} \mathrm{O}$ stretching vibration 278 (Wang et al. 2013b). The band at $490 \mathrm{~cm}^{-1}$ was assigned to the vibration of [ $\mathrm{TiO}_{6}$ ] 279 octahedron (Xiong et al. 2011). For TNT/C and TNT/HC, the new peak at $1384 \mathrm{~cm}^{-1}$ is 280 the carbonyl vibrations of ketone groups peak (Wang et al. 2013a). The 281 thermogravimetric profiles of TNT/C and TNT/HC could be seen in Figure 4.d. The 282 weight loss at temperatures below $100^{\circ} \mathrm{C}$ is due to the evaporation of free water on the 283 surface of the adsorbent (Yuan et al. 2017, Zhou et al. 2020). The weight loss at 100$284350^{\circ} \mathrm{C}$ is attributed to the loss of chemically bonded water of the crystal layer. The 285 weight loss after $350^{\circ} \mathrm{C}$ is due to the oxidation of carbon. TNT/HC has no obvious 286 plateau at $200-350^{\circ} \mathrm{C}$, which is caused by the superposition of the loss of chemically 287 bonded water in the crystal layer and the loss of carbon oxidation (Yuan et al. 2017).

\subsection{Effects of $\mathrm{pH}$}

The $\mathrm{pH}$ value of the experimental solution has a great influence on the adsorption results. According to previous studies, in order to avoid precipitation of $\mathrm{Cd}^{2+}$ hydroxide,

292 it was decided to choose an initial solution with a $\mathrm{pH}$ of 2-6 for exploration (Kim et al. 293 2020). The experimental results are shown in Figure 5. The adsorption capacity of TNT 294 and TNT/C for $\mathrm{Cd}^{2+}$ changes with the change of $\mathrm{pH}$, and the relationship between them is positively correlated. The maximum adsorption capacity occurs when the $\mathrm{pH}$ is 6 . 
296 Whether the adsorption mechanism is ion exchange or surface action, the adsorption of 297 positively charged $\mathrm{Cd}^{2+}$ and positively charged $\mathrm{H}^{+}$on the surface of the adsorbent is in 298 a competitive relationship. Therefore, when the $\mathrm{pH}$ is lower, the concentration of 299 hydrogen ions is also higher, and the competition between hydrogen ions and $\mathrm{Cd}^{2+}$ is 300 quite fierce. As we all know, $\mathrm{pH}$ is the negative logarithm of hydrogen ion. Because an 301 increase in the $\mathrm{pH}$ value by one value could cause the hydrogen ion concentration to 302 drop by an order of magnitude, so at the same time the ratio of $\mathrm{Cd}^{2+}$ to $\mathrm{H}^{+}$concentration 303 would increase. So, the adsorption capacity gradually increases with the increase of $\mathrm{pH}$.

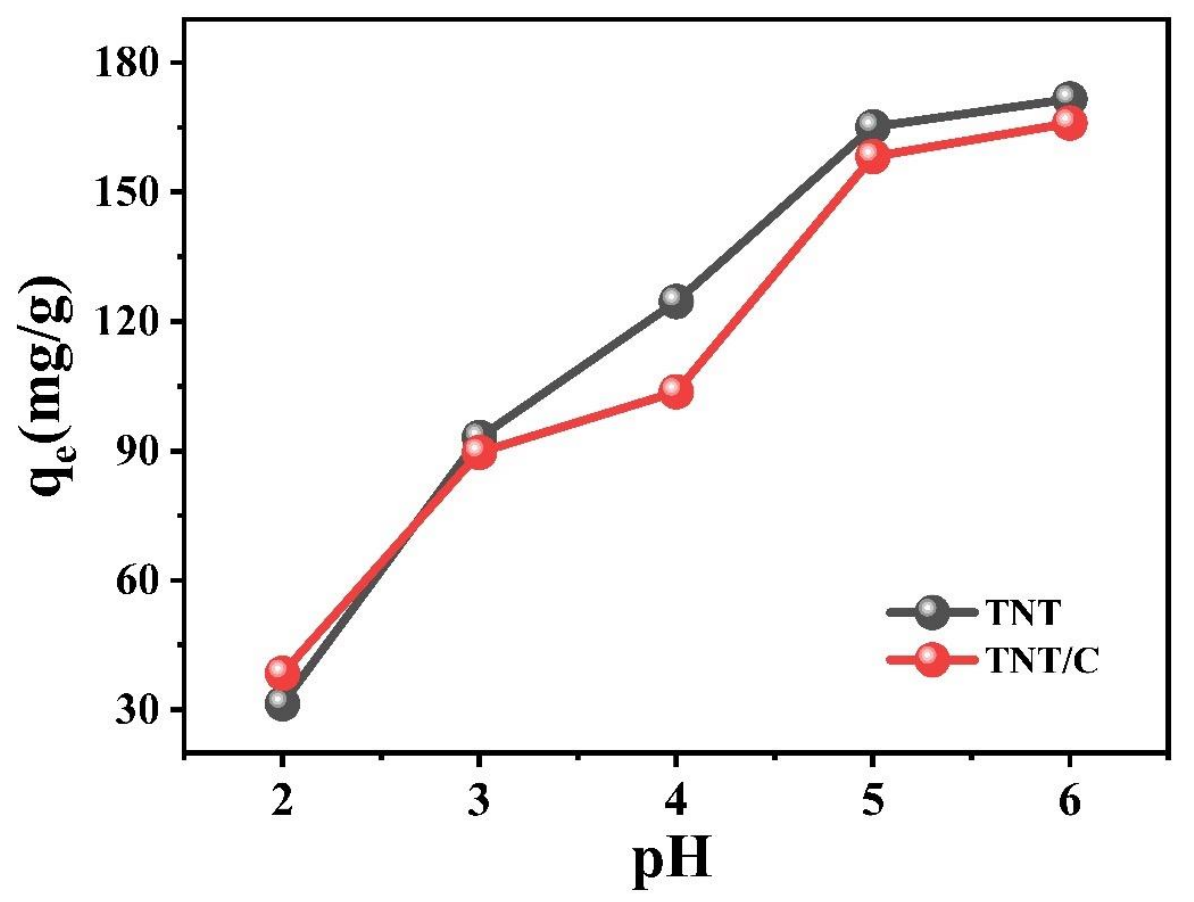
Fig. 5. Effect of initial pH on adsorption capacity of TNT and TNT/C.

\subsection{Effects of contact time and adsorption kinetic}

308 Figure 6.a shows the kinetics of $\mathrm{Cd}^{2+}$ adsorption on the TNT, TNT/C at $25{ }^{\circ} \mathrm{C}$ and $309 \mathrm{pH}=6$. Obviously, the adsorption capacity increases with the prolongation of the contact 310 time, and the adsorption equilibrium is reached within 150 minutes. The $\mathrm{Cd}^{2+}$ 311 absorption amounts of TNT, TNT/C are $171.56 \mathrm{mg} \cdot \mathrm{g}^{-1}$ and $166 \mathrm{mg} \cdot \mathrm{g}^{-1}$. Kinetic studies 312 have profound guiding significance for the explanation of the experimental mechanism 
and the selection of the best adsorption time for the adsorbent. There are two commonly

314 used semi-empirical models, namely pseudo-first-order (PFO) dynamics and pseudo-

315 second-order (PSO) dynamics (Dalvand et al. 2018, Dolatyari et al. 2016). The pseudo

316 first order dynamics is as follows $\square$

$317 \ln \left(q_{e}-q_{t}\right)=\ln q_{e}-k_{1} * t$

318 Where $k_{1}$ is the rate constant of pseudo-first-order adsorption, $q_{e}(\mathrm{mg} / \mathrm{g})$ and $q_{t}(\mathrm{mg} / \mathrm{g})$

319 is the amount of $\mathrm{Cd}^{2+}$ adsorbed at equilibrium and at time (t) (Goyal et al. 2020). The

320 pseudo first order dynamics is as follows $\square$

$321 t / q_{t}=1 /\left(k_{2} * q_{e}^{\wedge} 2\right)+t / q_{e}$

322 Where $k_{2}$ is the rate constant of pseudo-second-order adsorption (Rahman et al. 2020).

323 The corresponding kinetic parameters are shown in Table 1. The pseudo -first-order

324 kinetics and pseudo-second kinetics determination coefficient $\left(\mathrm{R}^{2}\right)$ of TNT/C are

3250.7623 and 0.9999 . Similarly, the value of $\mathrm{TNT} / \mathrm{HC}$ are 0.7396 and 0.9999 . This

326 indicates that pseudo-second-order kinetics is more suitable for the process of $\mathrm{Cd}^{2+}$

327 adsorption by TNT and TNT/C. Since the PSO model assumes that the chemical surface

328 reaction is the rate-limiting step (Zhao et al. 2020), we concluded that the rate-

329 determining step of $\mathrm{Cd}^{2+}$ adsorption on TNT and TNT/C was chemisorption (Zheng et

330 al. 2021).
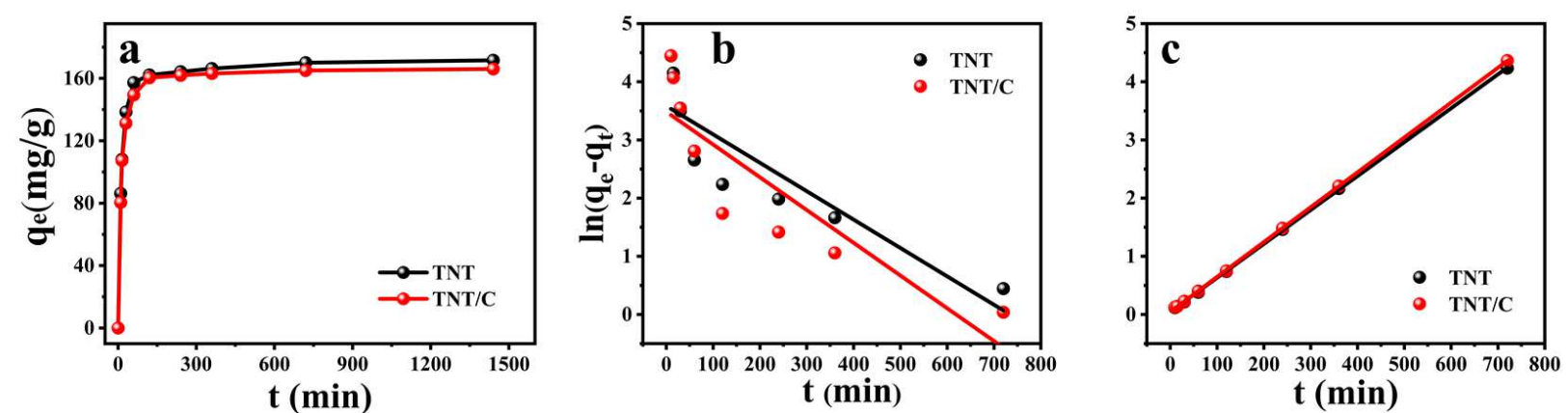

332 Fig. 6. Adsorption kinetics (a), the Pseudo-first-order model(b) and the Pseudosecond-order model fitting curve of $\mathrm{Cd}^{2+}$ on TNT and TNT/C (c).

334 Table 1

335 Pseudo-first-order and pseudo-second-order parameters for adsorption of $\mathrm{Cd}^{2+}$ by TNT 
pseudo-first-order kinetic pseudo-second-order kinetic

\begin{tabular}{|c|c|c|c|c|c|c|c|}
\hline \multirow{2}{*}{ Sample } & \multirow[b]{2}{*}{$\begin{array}{c}q_{e, \exp } \\
(\mathrm{mg} / \mathrm{g})\end{array}$} & \multirow[b]{2}{*}{$\begin{array}{c}q_{e, c a l} \\
(\mathrm{mg} / \mathrm{g})\end{array}$} & \multirow[b]{2}{*}{$\begin{array}{c}\mathrm{k}_{1} \\
\left(\min ^{-1}\right)\end{array}$} & \multirow[b]{2}{*}{$\mathrm{R}^{2}$} & \multirow[b]{2}{*}{$\begin{array}{c}q_{e, c a l} \\
(\mathrm{mg} / \mathrm{g})\end{array}$} & \multirow[b]{2}{*}{$\begin{array}{c}\mathrm{k}_{2} \\
\left(\mathrm{~g} /\left(\mathrm{mg}^{*} \min \right)\right)\end{array}$} & \multirow[b]{2}{*}{$\mathrm{R}^{2}$} \\
\hline & & & & & & & \\
\hline TNT & 171.56 & 36.0313 & 0.0049 & 0.7623 & 171.5266 & 0.4066 & 0.9999 \\
\hline $\mathrm{TNT} / \mathrm{C}$ & 166 & 32.6329 & 0.0056 & 0.7396 & 16.9449 & 0.3738 & 0.9999 \\
\hline
\end{tabular}

\subsection{Adsorption isotherms.}

339 For the design and operation of adsorption systems, the correlation of equilibrium 340 adsorption data is important. Langmuir and Freundlich isotherms models were applied 341 to fit the obtained adsorption data (Wang et al. 2020). The Langmuir equation has been 342 used extensively for dilute solutions in the following form:

$343 q_{e}=\left(q_{m} * K_{L} * c_{e}\right) /\left(1+K_{L} * c_{e}\right)$

344 Where $c_{e}\left(\mathrm{mg} \cdot \mathrm{L}^{-1}\right)$ is the equilibrium concentration of $\mathrm{Cd}^{2+}$ remained in solution, $345 q_{e}\left(\mathrm{mg} \cdot \mathrm{g}^{-1}\right)$ is the amount of solution adsorbed per unit mass of the adsorbent, $q_{m}$ $346\left(\mathrm{mg} \cdot \mathrm{g}^{-1}\right)$ is the maximum adsorption capacity, $K_{L}$ is the Langmuir adsorption 347 equilibrium constant (Tang et al. 2020). The Freundlich equation has been used 348 extensively for dilute solutions in the following form:

$349 \ln q_{e}=\ln K_{F}+1 / n * \ln c_{e}$

350 Where $K_{F}$ and $\mathrm{n}$ are the Freundlich constants related to the adsorption capacity 351 and adsorption intensity, respectively (Mao et al. 2018). The curve of the adsorption 352 isotherm model and the fitting data are shown in Figure 7 and Table 2. The results show 353 the Langmuir isotherm model better fits the experimental results with high correlation 354 coefficients $(>0.97)$. The Langmuir model indicates that it is monolayer adsorption on 355 the structurally homogeneous TNT and TNT/C. 


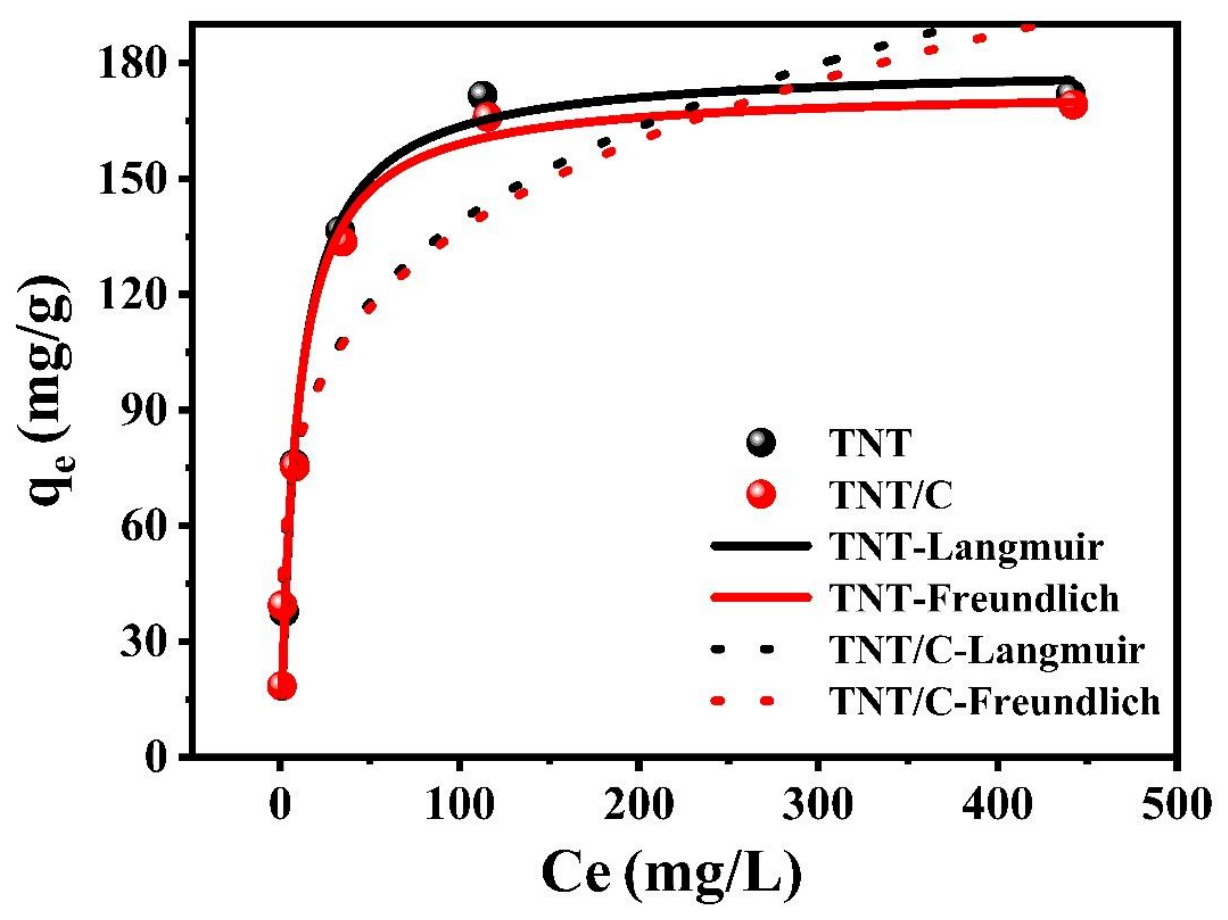

Fig. 7. Adsorption isotherm of $\mathrm{Cd}^{2+}$ on TNT and TNT/C

359 Table 2

360 Parameters of Langmuir and Freundlich isotherm models for the adsorption of $\mathrm{Cd}^{2+}$ on 361 TNT,TNT@C.

\begin{tabular}{|c|c|c|c|c|c|c|}
\hline \multirow[t]{2}{*}{ Samples } & \multicolumn{3}{|c|}{ Langmuir equation } & \multicolumn{3}{|c|}{ Freundlish equation } \\
\hline & $\begin{array}{c}q_{m} \\
\mathrm{mg} / \mathrm{g}\end{array}$ & $\begin{array}{c}\mathrm{K}_{\mathrm{L}} \\
\mathrm{L}^{\prime} \mathrm{mg}\end{array}$ & $\mathrm{R}^{2}$ & $\mathrm{~K}_{\mathrm{F}}$ & $\frac{1}{n}$ & $\mathrm{R}^{2}$ \\
\hline $\mathrm{TNT}$ & 179.37 & 0.1026 & 0.9951 & 47.0877 & 4.2597 & 0.8119 \\
\hline TNT/C & 173.31 & 0.1109 & 0.9806 & 47.5353 & 4.3662 & 0.8375 \\
\hline
\end{tabular}

3633.5 Effects of ionic strength $\left(\mathrm{Ca}^{2+}, \mathrm{Mg}^{2+}\right)$

364 Figure 8 shows the competition between coexisting cations and $\mathrm{Cd}^{2+}$ on TNT, 365 TNT/C and TNT/HC. Generally, the adsorption capacity of $\mathrm{Cd}^{2+}$ will decrease in the 
presence of $\mathrm{Ca}^{2+}$ or $\mathrm{Mg}^{2+}$ (Liu et al. 2013). This is due to the competition adsorption between $\mathrm{Ca}^{2+}$ or $\mathrm{Mg}^{2+}$ and $\mathrm{Cd}^{2+}$. In this paper, the adsorption capacity of $\mathrm{Cd}^{2+}$ also decreases when $\mathrm{Ca}^{2+}$ or $\mathrm{Mg}^{2+}$ exists in the adsorption environment, but the adsorption capacity of TNT/C and TNT/HC exceeds that of $\mathrm{Cd}^{2+}$ absorbed by TNT due to the loading of carbon. When $\mathrm{Ca}^{2+}$ or $\mathrm{Mg}^{2+}$ exists in the adsorption environment, the order of the adsorption capacity of $\mathrm{Cd} 2+$ to different adsorption materials is $\mathrm{TNT} / \mathrm{HC}>\mathrm{TNT} / \mathrm{C}>\mathrm{TNT}$. But the order of adsorption capacity is $\mathrm{TNT}>\mathrm{TNT} / \mathrm{C}>\mathrm{TNT} / \mathrm{HC}$ in the absence of $\mathrm{Ca}^{2+}$ or $\mathrm{Mg}^{2+}$. It is also interesting to see that the anti-interference ability of TNT/HC prepared by hydrothermal method is improved after the carbon on the surface of $\mathrm{TiO} 2$ is oxidized by nitric acid (TNT/HC). The experimental results also show that when the concentration of $\mathrm{Ca}^{2+}$ or $\mathrm{Mg}^{2+}$ is high up to $0.1 \mathrm{~mol} / \mathrm{L}$, the adsorption capacity of TNT/HC on $\mathrm{Cd}^{2+}$ increases from $44.28 \mathrm{mg} / \mathrm{L}$ to $65.52 \mathrm{mg} / \mathrm{L}$ (in the presence of $\mathrm{Ca}^{2+}$ ), and from $49.04 \mathrm{mg} / \mathrm{L}$ to $66.6 \mathrm{mg} / \mathrm{L}$ (in the presence of $\mathrm{Mg}^{2+}$ ) compared with TNT. It is proved that TNT/HC is more promising than TNT as an adsorbent for the selective separation of $\mathrm{Cd}^{2+}$ from complex water conditions.
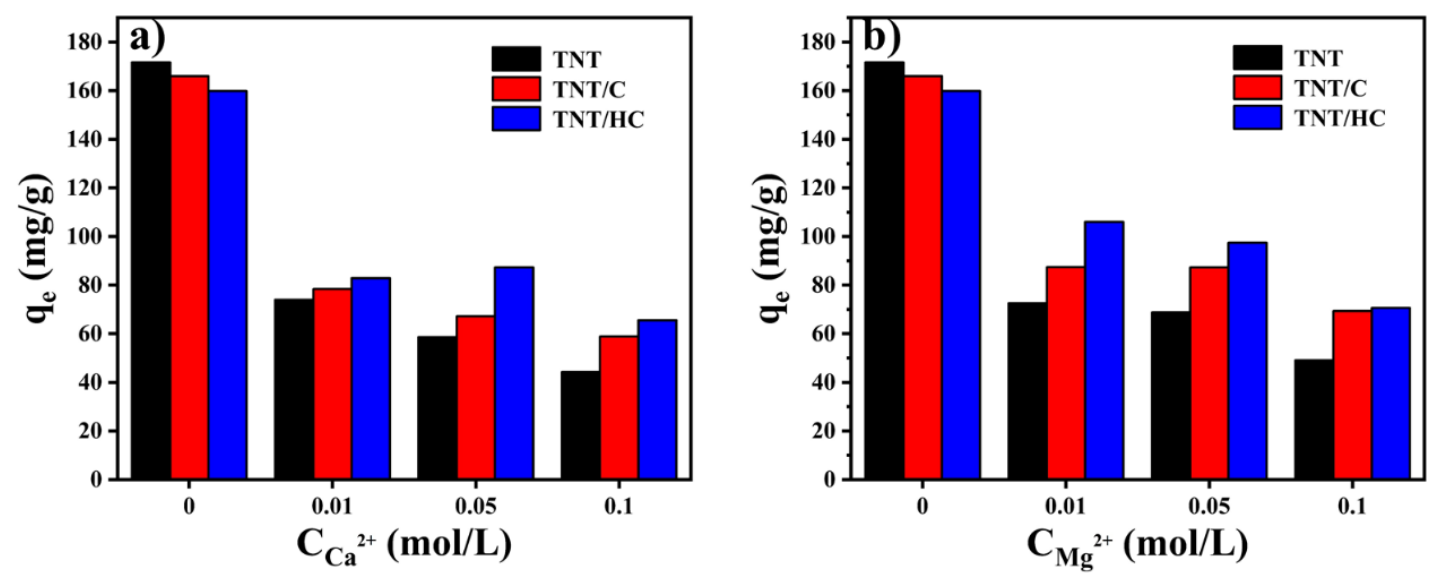

Fig. 8. The adsorption capacity of $\mathrm{Cd}^{2+}$ on TNTs, TNTs/C and TNTs/HC with or without the presence of $\mathrm{Ca}^{2+}(\mathrm{a})$ or $\mathrm{Mg}^{2+}(\mathrm{b})$. 
In order to reveal the competitive adsorption mechanism of TNT based adsorbents to metal ions, we tested the XPS spectra of adsorbents before and after adsorption. The experimental results are shown in the figure 9. In the wide-scan spectrum, after the 390 adsorption of $\mathrm{Cd}^{2+}, \mathrm{Ca}^{2+}$, and $\mathrm{Mg}^{2+}$, the peaks of sodium ions almost disappeared, and

$391 \mathrm{Cd}^{2+}, \mathrm{Ca}^{2+}$, and $\mathrm{Mg}^{2+}$ peaks appeared, which indicates that the adsorption of $\mathrm{Cd}^{2+}, \mathrm{Ca}^{2+}$, 392 and $\mathrm{Mg}^{2+}$ are achieved (Huang et al. 2020b). This reveals that the main adsorption 393 mechanism is the sodium ion exchange with metal ions in the TNT layers. In the narrow 394 sweep of $\mathrm{C} 1 \mathrm{~s}$, the peaks at $284.8,286.5$, and $288.8 \mathrm{eV}$ represent $\mathrm{C}=\mathrm{C} / \mathrm{C}-\mathrm{C}, \mathrm{C}-\mathrm{O}$, and $395 \mathrm{C}=\mathrm{O}$, respectively (Yang et al. 2020). After the adsorption of $\mathrm{Cd}^{2+}$, the $\mathrm{C}=\mathrm{C} / \mathrm{C}-\mathrm{C}$ peak 396 decreased (from $57.79 \%$ to $44.45 \%$ ). This indicates that the cadmium ion- $p$ effect 397 supports the loading of $\mathrm{Cd}^{2+}$ on $\mathrm{C}$. In the $\mathrm{Cd}^{2+}+\mathrm{Ca}^{2+}$ and $\mathrm{Cd}^{2+}+\mathrm{Mg}^{2+}$ systems, the $\mathrm{C}=\mathrm{C}$ 398 and C-O peak decreases after adsorption (Yuan et al. 2020). This can be explained by 399 the theory of hard and soft acids and bases: $\mathrm{Ca}^{2+}$ and $\mathrm{Mg}^{2+}$ belong to the ranks of hard 400 acids and C-O belongs to hard base, while $\mathrm{Cd}^{2+}$ is classified as soft acid. it is caused by 401 the complexation of $\mathrm{C}-\mathrm{O}$ to $\mathrm{Ca}^{2+}$ and $\mathrm{Mg}^{2+}$, while $\mathrm{C}-\mathrm{O}$ is not interested in $\mathrm{Cd}^{2+}$. This is 402 why the adsorption capacity of TNT/C is greater than that of neat TNT. And the 403 experimental data shows that there is $\mathrm{Ca}^{2+}$ or $\mathrm{Mg}^{2+}$ in the water, the order of $\mathrm{Cd}^{2+}$ 404 adsorption is TNT/HC $>$ TNT/C $>$ TNT, which is consistent with the order of C-O content. 

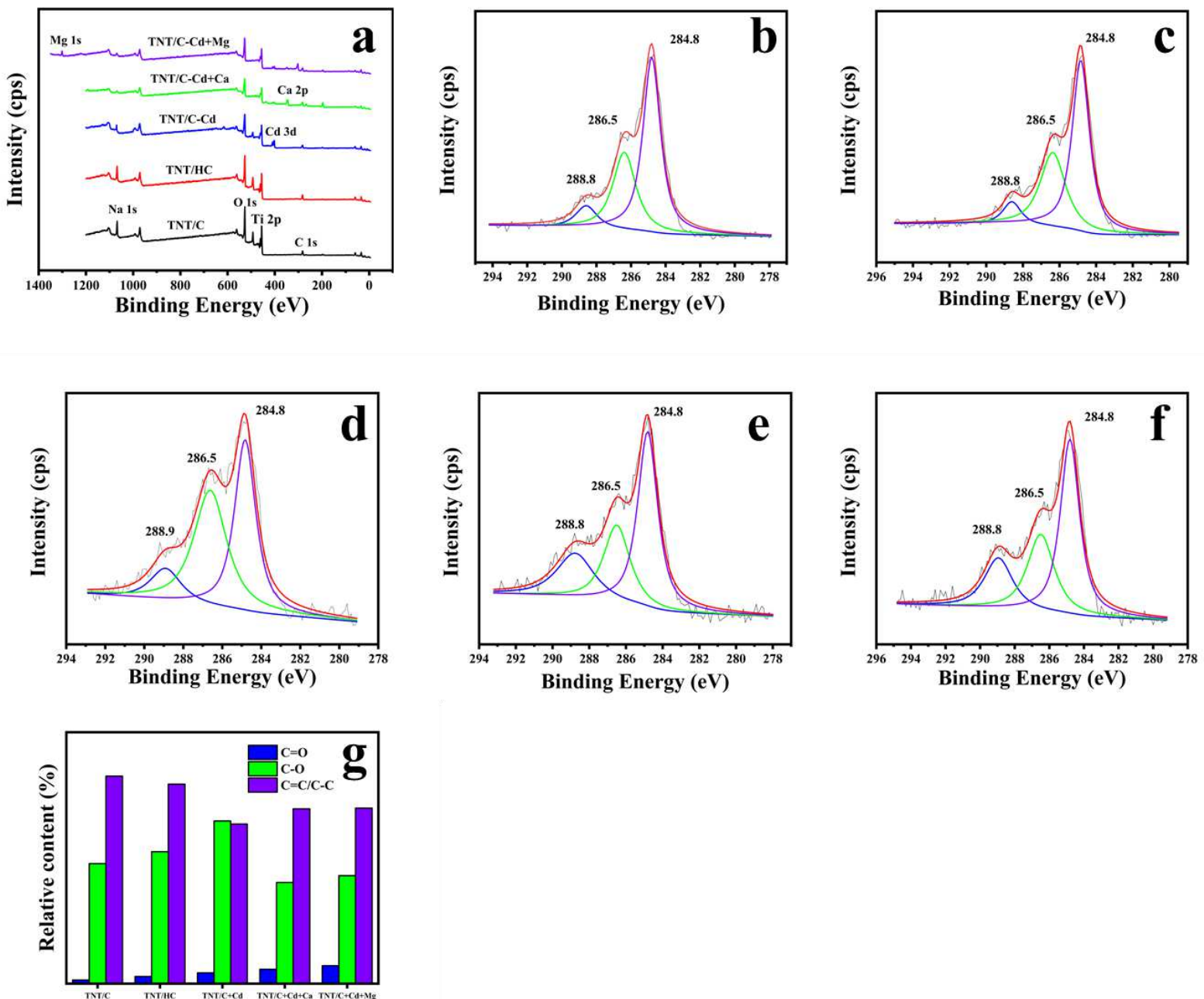

Fig. 9. XPS wide-scan spectra (a); C1s XPS spectra off TNT/C(b), TNT/HC(c), TNT/HC-Cd(d), TNT/C-Cd $+\mathrm{Ca}(\mathrm{e})$ and TNT/C-Cd $+\mathrm{Mg}(\mathrm{f})$; (g) the content of carboncontaining functional groups in the adsorbent before and after adsorption.

\section{Conclusions}

411 We successfully synthesized titanate nanotubes and compounded a layer of carbon

412 on the surface of titanate nanotubes in situ. A series of characterization of the 413 synthesized adsorbent were carried by SEM, TEM and XRD. The characterization 414 results show that the modification of carbon does not affect the formation of titanate 415 nanotubes. Through experiments, we have obtained the optimal $\mathrm{pH}$ value for $\mathrm{Cd}^{2+}$ 416 adsorption by TNT and TNT/C which is $\mathrm{pH}=6$; the pseudo-second-order kinetic model 
and Langmuir isotherm adsorption model are more suitable for the adsorption process,

418 which means chemical adsorption and single-layer adsorption occurs during the 419 adsorption of $\mathrm{Cd}^{2+}$ on TNT and TNT/C. However, the fact that $\mathrm{Ca}^{2+}$ and $\mathrm{Mg}^{2+}$ inhibit 420 the adsorption of $\mathrm{Cd}^{2+}$ on titanate nanotubes is well known. We set out to solve this 421 problem by loading a layer of carbon in situ on the surface of TNT and then activating 422 it with strong acid. Experimental results show that this procedure improved the competitive adsorption of $\mathrm{Cd}^{2+}$ in the presence of $\mathrm{Ca}^{2+}$ or $\mathrm{Mg}^{2+}$. Although the surface

424 loading of a layer of carbon lowers the total adsorption capacity of titanate nanotubes 425 for ions (the order of adsorption capacity is TNT $>$ TNT/C $>$ TNT/HC in the absence of $426 \mathrm{Ca}^{2+}$ or $\mathrm{Mg}^{2+}$ ), it improves its ability of resist interference from $\mathrm{Ca}^{2+}$ and $\mathrm{Mg}^{2+}$ (the 427 order of adsorption capacity of $\mathrm{Cd}^{2+}$ on different adsorption materials is $428 \mathrm{TNT} / \mathrm{HC}>\mathrm{TNT} / \mathrm{C}>\mathrm{TNT}$ in the presence of $\mathrm{Ca}^{2+}$ or $\left.\mathrm{Mg}^{2+}\right)$. Although it is not the first 429 time to pay attention to the influence of $\mathrm{Ca}^{2+}$ and $\mathrm{Mg}^{2+}$ on titanate nanotube adsorbent, 430 as far as we know, this is the first time to try to solve this problem and get a positive 431 response. This paper provides an idea for the research and development of heavy metal 432 ion adsorbents.

\section{Declarations}

434 Ethics approval and consent to participate: Not applicable.

435 Consent for publication: Not applicable.

436 Availability of data and materials: All data generated or analysed during this study 437 are included in this published article.

438 Conflicts of interest: The authors declare no conflict of interest.

439 Funding: This research received no external funding.

440 Author Contributions: This research was designed, implemented and written by Mr. 441 Mingda Wu; the research was supervised by Ms. Tao Zhou. Mr. Yi Ma and Zhengsong 442 Weng performed statistical analysis, Professor Linghong Lu provided laboratory 443 support.

444 Acknowledgements: The project gets the funding support from the National Natural 
Science Foundation of China (NO.21676137 and NO.21838004).

\section{References}

Bi J, Huang X, Wang J, Tao Q, Wang T, Hao H (2020): Titanate for water remediation: synthesis, application, mechanism and optimization. Journal of Materials Chemistry A 8, 14415-14440

Bolisetty S, Peydayesh M, Mezzenga R (2019): Sustainable technologies for water purification from heavy metals: review and analysis. Chem Soc Rev 48, 463487

Boparai HK, Joseph M, O'Carroll DM (2011): Kinetics and thermodynamics of cadmium ion removal by adsorption onto nano zerovalent iron particles. J Hazard Mater 186, $458-65$

Dalvand A, Khoobi M, Nabizadeh R, Ganjali MR, Gholibegloo E, Mahvi AH (2018): Reactive Dye Adsorption from Aqueous Solution on HPEI-Modified Fe304 Nanoparticle as a Superadsorbent: Characterization, Modeling, and Optimization. Journal of Polymers and the Environment 26, 3470-3483

Di Natale F, Gargiulo V, Alfe M (2020): Adsorption of heavy metals on silica-supported hydrophilic carbonaceous nanoparticles (SHNPs). J Hazard Mater 393, 122374

Dolatyari L, Yaftian MR, Rostamnia S (2016): Removal of uranium(VI) ions from aqueous solutions using Schiff base functionalized SBA-15 mesoporous silica materials. J Environ Manage 169, 8-17

Du AJ, Sun DD, Leckie J0 (2011): Sequestration of cadmium ions using titanate nanotube. J Hazard Mater 187, 401-6

Duan J, Ji H, Xu T, Pan F, Liu X, Liu W, Zhao D (2021): Simultaneous adsorption of uranium(VI) and 2-chlorophenol by activated carbon fiber supported/modified titanate nanotubes (TNTs/ACF): Effectiveness and synergistic effects. Chemical Engineering Journal 406

Esrafili L, Firuzabadi FD, Morsali A, Hu ML (2021): Reuse of Predesigned DualFunctional Metal Organic Frameworks (DF-MOFs) after Heavy Metal Removal. J Hazard Mater 403, 123696

Goyal N, Gao P, Wang Z, Cheng S, Ok YS, Li G, Liu L (2020): Nanostructured chitosan/molecular sieve-4A an emergent material for the synergistic adsorption of radioactive major pollutants cesium and strontium. J Hazard Mater 392, 122494

Huang K, Lv X, Guan X, Liu J, Li S, Song H (2020a): Advanced Cd (II) adsorbent fabricated with hordein from barley (Hordeum vulgare L.) via electrospinning technology. Industrial Crops and Products 152

Huang X, Zhao H, Hu X, Liu F, Wang L, Zhao X, Gao P, Ji P (2020b): Optimization of preparation technology for modified coal fly ash and its adsorption properties for Cd(2). J Hazard Mater 392, 122461

Kasuga T, Hiramatsu M, Hoson A, Sekino T, Niihara K (1998): Formation of titanium oxide nanotube. Langmuir 14, 3160-3163 
Kim D-W, Wee J-H, Yang C-M, Yang KS (2020): Efficient removals of $\mathrm{Hg}$ and $\mathrm{Cd}$ in aqueous solution through NaOH-modified activated carbon fiber. Chemical Engineering Journal 392

Li X, Liu W, Ni J (2015): Short-cut synthesis of tri-titanate nanotubes using nanoanatase: Mechanism and application as an excellent adsorbent. Microporous and Mesoporous Materials 213, 40-47

Liu W, Wang T, Borthwick AGL, Wang Y, Yin X, Li X, Ni J (2013): Adsorption of Pb2+, $\mathrm{Cd} 2+, \mathrm{Cu} 2+$ and $\mathrm{Cr} 3+$ onto titanate nanotubes: Competition and effect of inorganic ions. Science of The Total Environment 456-457, 171-180

Liu W, Sun W, Han Y, Ahmad M, Ni J (2014): Adsorption of Cu(II) and Cd(II) on titanate nanomaterials synthesized via hydrothermal method under different $\mathrm{NaOH}$ concentrations: Role of sodium content. Colloids and Surfaces A: Physicochemical and Engineering Aspects 452, 138-147

Lu F, Astruc D (2018): Nanomaterials for removal of toxic elements from water. Coordination Chemistry Reviews 356, 147-164

Ma J, Li F, Qian T, Liu H, Liu W, Zhao D (2017): Natural organic matter resistant powder activated charcoal supported titanate nanotubes for adsorption of $\mathrm{Pb}(\mathrm{II})$. Chemical Engineering Journal 315, 191-200

Mahdavi S, Jalali M, Afkhami A (2013): HEAVY METALS REMOVAL FROM AQUEOUS SOLUTIONS USING Ti02, Mg0, AND A1203NANOPARTICLES. Chemical Engineering Communications 200, $448-470$

Mao X, Wang L, Gu S, Duan Y, Zhu Y, Wang C, Lichtfouse E (2018): Synthesis of a three-dimensional network sodium alginate-poly(acrylic acid)/attapulgite hydrogel with good mechanic property and reusability for efficient adsorption of $\mathrm{Cu} 2+$ and $\mathrm{Pb} 2+$. Environmental Chemistry Letters 16, 653-658

Maroto-Valer MM, Dranca I, Lupascu T, Nastas R (2004): Effect of adsorbate polarity on thermodesorption profiles from oxidized and metal-impregnated activated carbons. Carbon 42, 2655-2659

Mudhoo A, Ramasamy DL, Bhatnagar A, Usman M, Sillanpaa M (2020): An analysis of the versatility and effectiveness of composts for sequestering heavy metal ions, dyes and xenobiotics from soils and aqueous milieus. Ecotoxicol Environ Saf 197, 110587

Pyrzyńska K, Bystrzejewski M (2010): Comparative study of heavy metal ions sorption onto activated carbon, carbon nanotubes, and carbon-encapsulated magnetic nanoparticles. Colloids and Surfaces A: Physicochemical and Engineering Aspects 362, 102-109

Rahman ML, Fui CJ, Sarjadi MS, Arshad SE, Musta B, Abdullah MH, Sarkar SM, 0’ Reilly EJ (2020): Poly(amidoxime) ligand derived from waste palm fiber for the removal of heavy metals from electroplating wastewater. Environ Sci Pollut Res Int

Sriram G, Kigga M, Uthappa UT, Rego RM, Thendral V, Kumeria T, Jung HY, Kurkuri MD (2020): Naturally available diatomite and their surface modification for the 
removal of hazardous dye and metal ions: A review. Adv Colloid Interface Sci 282, 102198

Tang C, Brodie P, Li Y, Grishkewich NJ, Brunsting M, Tam KC (2020): Shape recoverable and mechanically robust cellulose aerogel beads for efficient removal of copper ions. Chemical Engineering Journal 392

Wang Q, Lei X, Pan F, Xia D, Shang Y, Sun W, Liu W (2018): A new type of activated carbon fibre supported titanate nanotubes for high-capacity adsorption and degradation of methylene blue. Colloids and Surfaces A: Physicochemical and Engineering Aspects 555, 605-614

Wang R, Chen H, Xiao Y, Hadar I, Bu K, Zhang X, Pan J, Gu Y, Guo Z, Huang F, Kanatzidis MG (2019): Kx[Bi4-xMnxS6], Design of a Highly Selective Ion Exchange Material and Direct Gap 2D Semiconductor. J Am Chem Soc 141, 1690316914

Wang T, Liu W, Xiong L, Xu N, Ni J (2013a): Influence of pH, ionic strength and humic acid on competitive adsorption of $\mathrm{Pb}(\mathrm{II}), \mathrm{Cd}(\mathrm{II})$ and $\mathrm{Cr}$ (III) onto titanate nanotubes. Chemical Engineering Journal 215-216, 366-374

Wang T, Liu W, Xu N, Ni J (2013b): Adsorption and desorption of Cd(II) onto titanate nanotubes and efficient regeneration of tubular structures. Journal of Hazardous Materials 250-251, 379-386

Wang Z, Wu S, Zhang Y, Miao L, Zhang Y, Wu A (2020): Preparation of modified sodium alginate aerogel and its application in removing lead and cadmium ions in wastewater. Int J Biol Macromol 157, 687-694

Xiong L, Chen C, Chen Q, Ni J (2011): Adsorption of $\mathrm{Pb}(\mathrm{II}$ ) and $\mathrm{Cd}$ (II) from aqueous solutions using titanate nanotubes prepared via hydrothermal method. J Hazard Mater 189, 741-8

Yang X, Guo N, Yu Y, Li H, Xia H, Yu H (2020): Synthesis of magnetic graphene oxidetitanate composites for efficient removal of $\mathrm{Pb}$ (II) from wastewater: Performance and mechanism. Journal of Environmental Management 256

Yuan F, Wu C, Cai Y, Zhang L, Wang J, Chen L, Wang X, Yang S, Wang S (2017): Synthesis of phytic acid-decorated titanate nanotubes for high efficient and high selective removal of U(VI). Chemical Engineering Journal 322, 353-365

Yuan S, Hong M, Li H, Ye Z, Gong H, Zhang J, Huang Q, Tan Z (2020): Contributions and mechanisms of components in modified biochar to adsorb cadmium in aqueous solution. Sci Total Environ 733, 139320

Yusuf M, Song K, Geng S, Fazhi X (2020): Adsorptive removal of anionic dyes by graphene impregnated with Mn02 from aqueous solution. Colloids and Surfaces A: Physicochemical and Engineering Aspects 595

Zhang J, Hou D, Shen Z, Jin F, O’Connor D, Pan S, Ok YS, Tsang DCW, Bolan NS, Alessi DS (2020): Effects of excessive impregnation, magnesium content, and pyrolysis temperature on $\mathrm{Mg} 0$-coated watermelon rind biochar and its lead removal capacity. Environmental Research 183

Zhang S, Cui M, Chen J, Ding Z, Wang X, Mu Y, Meng C (2019): Modification of synthetic 
zeolite X by thiourea and its adsorption for Cd (II). Materials Letters 236, $233-235$

Zhao F, Yang Z, Wei Z, Spinney R, Sillanpää M, Tang J, Tam M, Xiao R (2020): Polyethylenimine-modified chitosan materials for the recovery of La(III) from leachates of bauxite residue. Chemical Engineering Journal 388

Zhao G, Li J, Ren X, Chen C, Wang X (2011): Few-layered graphene oxide nanosheets as superior sorbents for heavy metal ion pollution management. Environ Sci Technol 45, 10454-62

Zhao X, Cai Z, Wang T, 0' Reilly SE, Liu W, Zhao D (2016): A new type of cobaltdeposited titanate nanotubes for enhanced photocatalytic degradation of phenanthrene. Applied Catalysis B: Environmental 187, 134-143

Zheng C, Wu Q, Hu X, Wang Y, Chen Y, Zhang S, Zheng H (2021): Adsorption behavior of heavy metal ions on a polymer-immobilized amphoteric biosorbent: Surface interaction assessment. Journal of Hazardous Materials 403

Zhou G, Luo J, Liu C, Chu L, Crittenden J (2018): Efficient heavy metal removal from industrial melting effluent using fixed-bed process based on porous hydrogel adsorbents. Water Res 131, 246-254

Zhou Y, Li Y, Liu D, Wang X, Liu D, Xu L (2020): Synthesis of the inorganic-organic hybrid of two-dimensional polydopamine-functionalized titanate nanosheets and its efficient extraction of $\mathrm{U}(\mathrm{VI})$ from aqueous solution. Colloids and Surfaces A: Physicochemical and Engineering Aspects 607

Zhu J, Liu Q, Li Z, Liu J, Zhang H, Li R, Wang J (2018): Efficient extraction of uranium from aqueous solution using an amino-functionalized magnetic titanate nanotubes. J Hazard Mater 353, 9-17 